\title{
O gênero como o denominador comum nas diferentes perspectivas penais da disposição e exposição não autorizadas da intimidade feminina
}

\author{
The gender as the common denominator in the different criminal perspectives of \\ the unauthorized disposal and exposition of female intimacy
}

\author{
Artenira da Silva e Silva* \\ Rossana Barros Pinheiro*
}

\section{Resumo}

A exposição não autorizada da intimidade feminina tem se apresentado como prática criminosa de larga incidência na modernidade, período em que o patriarcado e a violência contra as mulheres são instrumentalizados através dos dispositivos tecnológicos, demonstrando, assim, que virtual e presencial não são processos de socialização apartados, mas se sobrepõem a fim de reafirmar os binarismos de gênero. A exposição não autorizada da sexualidade feminina pode estar associada a variadas motivações, como vingança ante traições ou términos afetivos, sextorsão, constrangimento ilegal e ameaças, condutas que podem ferir bens jurídicos penais diferentes, como a integridade física e psicológica, o patrimônio e a liberdade, exigindo, dessa forma, tipificações penais específicas. Apesar de tais variações quanto às condutas e motivações vislumbradas nos referidos crimes, o gênero apresenta-se como denominador comum em todas as perspectivas de exposição da intimidade feminina, haja vista a imposição de constrangimento às vítimas e naturalização da conduta delituosa do agressor. Para realização do presente estudo, adotaram-se marcos teóricos sociólogos como Simone de Beauvoir, Bourdieu e Naomi Wolff, dedicados à análise do gênero enquanto elemento social, psicológico e jurídico. Na perspectiva penal, utilizaram-se como fontes teóricas autores como Damásio de Jesus, Cezar Bitencourt e Maria Berenice Dias. Como metodologia de pesquisa, adotaram-se a pesquisa bibliográfica e a análise de dados estatísticos.

Palavras-chave: Violência. Gênero. Estupro virtual. Ameaças. Pornografia de vingança.

\section{Abstract}

The forced exposure of feminine intimacy is as a recurrent criminal practice nowadays in which patriarchy and violence against women are instrumentalized through technological devices, demonstrating that virtual and presencial social interactions are both different kinds of real social interactions. They both continue to reaffirm gender binarisms. The exposure of female intimacy may be associated with a variety of motives such the revenge for betrays or the end of relationships, leading to extortion, rape, illegal constraint and threats, violating different women's rights, such as physical and psychological integrity, patrimony and freedom. Although these different violations of rights can easily be perceived in crimes against women, gender is a common denominator in all perspectives of female intimacy exposure, because of the common imposition of guilt over the victims due to the social naturalization of the abuser's conduct. For the realization of the present study, we analyze sociologists such as Simone de Beauvoir, Bourdieu and Naomi Wolff, who are dedicated to analyzing gender as a social, psychological and legal phenomenon. In the penal perspective, authors such as Damásio de Jesus, Cezar Bitencourt and Maria Berenice Dias will be used as theoretical fonts. As a research methodology, the bibliographic research and analysis of statistic data will be adhered to.

Keywords: Violence. Gender. Virtual rape. Threats. Revenge porn.

Pós-doutora em Psicologia e Educação pela Universidade do Porto. Doutora em Saúde Coletiva pela Universidade Federal da Bahia. Mestre em Saúde e Ambiente pela Universidade Federal do Maranhão. Graduada em Psicologia pela Pontifícia Universidade Católica de São Paulo. Docente e Pesquisadora do Departamento de Saúde Pública e do Programa de Pós-Graduação em Direito e Instituições do Sistema de Justiça/UFMA. Coordenadora da Linha de Pesquisa do Observatório Ibero Americano de Saúde e Cidadania e Coordenadora do Observatorium de Segurança Pública (PPGDIRUFMA/CECGP). Psicóloga Clínica e Forense. São Luís - MA - Brasil. E-mail: artenirassilva@hotmail.com.

Mestranda do Programa de Pós-Graduação em Direito e Instituições do Sistema de Justiça. Graduada em Direito pela Universidade Federal do Maranhão. Membro da Equipe da Revisão da Revista do Curso de Direito. Membro do Núcleo de Estudos de Direito Constitucional. Bolsista da CAPES. Advogada. São Luís - MA - Brasil. E-mail: rossana.barros@hotmail.com. 


\section{Introdução}

A exposição intencional e deliberada da intimidade feminina, seja como vingança ante término ou traição afetiva, seja como forma de extorsão, com a finalidade de obter vantagens patrimoniais e/ou sexuais, seja como manifestação do simples desejo de constranger mulheres em público, é uma prática que tem apresentado larga incidência na modernidade.

Nessa perspectiva, os dispositivos tecnológicos contemporâneos, utilizados em uma conjuntura marcada pelo elevado padrão de comunicação instantânea e interatividade, permitem uma repercussão assustadora da intimidade da mulher nos espaços de convivência presencial e virtual, haja vista a circulação e reprodução de conteúdos de natureza confidenciais em escala planetária.

Considerando a vigência de diferenciações de gênero que castram o exercício da sexualidade feminina no âmbito das sociedades machistas, em quaisquer modalidades de exposições íntimas, motivadas pelas mais diferentes explicações e efetivadas mediante os diversos meios, a exposição da intimidade feminina sempre constitui um tabu sujeito à reprovação e escárnio sociais, inclusive no âmbito do sistema de justiça brasileiro. Dessa forma, o gênero é um denominador comum em todas as perspectivas da exposição da intimidade feminina, implicando na invisibilização da violência sofrida e naturalização da atitude criminosa do agressor.

Diante do exposto, o presente estudo objetivou analisar as diferentes perspectivas de exposição da intimidade feminina, como sextorsão, estupro virtual, constrangimento ilegal, ameaça e pornografia de vingança, pontuando os fatores de distanciamento entre os crimes em questão e o gênero enquanto denominador comum, atravessando-os. Tal abordagem se revela útil à medida que contribui para esclarecer a natureza jurídica dessas condutas que, contextualizadas com a velocidade e fluidez típicos da era virtual, implicam em dúvidas quanto à aplicação do Direito e dificuldades institucionais de enfrentamento efetivo do problema.

\section{A exposição da sexualidade feminina como uma violência de gênero crescente no mundo}

O ato de transpor a sexualidade feminina, exercida no âmbito da intimidade, ao espaço público é, por si somente, uma conduta que tem como plano de fundo as diferenciações de gênero, considerando a consciência que têm o agressor e a vítima de que o conteúdo terá inevitável repercussão negativa, implicando danos irreparáveis e irreversíveis para a mulher nas perspectivas individual e pública.

Nesse contexto, seja por motivo de vingança ante término ou infidelidade afetiva, seja por motivo de extorsão patrimonial e/ou sexual, seja por motivo de cyberbullying, ter a intimidade amplamente revelada e julgada no âmbito familiar, profissional, religioso, moral e social, constitui um pesadelo para as mulheres na maior parte das sociedades ocidentais, marcadas pelo machismo.

Aproveitando-se da confiança depositada por suas vítimas, materializada através do compartilhamento de conteúdo sensual ou na permissão para registro de momentos íntimos, os agressores frequentemente utilizam o material obtido como subsídios para o estabelecimento de ameaças. Essa coerção psicológica é comumente utilizada para forçar a continuidade de relacionamentos abusivos, configurando o crime de constrangimento ilegal; para obter vantagens patrimoniais, configurando o delito de extorsão; para obter vantagens sexuais, no caso do crime de estupro virtual; e para vingar-se perante término de um relacionamento afetivo e/ou sexual, configurando pornografia de vingança.

Conviver com esse constrangimento, quando a sexualidade é, de fato, descortinada em público, ou quando se restringe ao plano das ameaças, implica na perturbação do equilíbrio emocional e fisiológico das vítimas, que frequentemente apresentam ideações suicidas. Nesse sentido, pesquisa realizada pela organização Cyber Civil Rights constatou que 51\% das mulheres que tiveram sua sexualidade exposta apresentaram pensamentos suicidas após a disponibilização do conteúdo íntimo (FRANKS, 2015). 
Essa vulnerabilidade da saúde feminina, fragilizada por efeito das ameaças de divulgação do conteúdo sob a posse do agressor, decorre da prática de violência psicológica, moral, sexual e patrimonial, condutas previstas textualmente na Lei Maria da Penha, que podem ser vislumbradas quando a intimidade de uma mulher é transposta para a perspectiva pública.

Art. $7^{\circ}$ São formas de violência doméstica e familiar contra a mulher, entre outras:

[...] II - a violência psicológica, entendida como qualquer conduta que lhe cause dano emocional e diminuição da autoestima ou que lhe prejudique e perturbe o pleno desenvolvimento ou que vise degradar ou controlar suas ações, comportamentos, crenças e decisões, mediante ameaça, constrangimento, humilhação, manipulação, isolamento, vigilância constante, perseguição contumaz, insulto, chantagem, ridicularização, exploração e limitação do direito de ir e vir ou qualquer outro meio que the cause prejuízo à saúde psicológica e à autodeterminação;

III - a violência sexual, entendida como qualquer conduta que a constranja a presenciar, a manter ou a participar de relação sexual não desejada, mediante intimidação, ameaça, coação ou uso da força; que a induza a comercializar ou a utilizar, de qualquer modo, a sua sexualidade, que a impeça de usar qualquer método contraceptivo ou que a force ao matrimônio, à gravidez, ao aborto ou à prostituição, mediante coação, chantagem, suborno ou manipulação; ou que limite ou anule o exercício de seus direitos sexuais e reprodutivos;

IV - a violência patrimonial, entendida como qualquer conduta que configure retenção, subtração, destruição parcial ou total de seus objetos, instrumentos de trabalho, documentos pessoais, bens, valores e direitos ou recursos econômicos, incluindo os destinados a satisfazer suas necessidades; $\mathrm{V}$ - a violência moral, entendida como qualquer conduta que configure calúnia, difamação ou injúria.

A exposição não consentida da intimidade feminina consiste em violência psicológica à proporção que ameaça, significativamente, a saúde psicológica e o pleno desenvolvimento mental de suas vítimas, haja vista o constrangimento a partir de ameaças, redução do sentimento de autoestima e assunção de culpa, fenômeno reflexo da violência de gênero.

Essa perturbação da saúde psicológica experimentada repercute sensivelmente sobre a integridade física das mulheres ofendidas, raciocínio corroborado pela literatura médica e, paulatinamente, sedimentado na cultura jurídica brasileira. Autores como Aníbal Bruno (1976) esclarecem que perturbações ao psiquismo podem originar lesões corporais a partir de estados de inconsciência ou insensibilidade, determinados pelo uso de anestésicos ou inebriantes, episódios de depressão, desmaios e estados confusionais, por exemplo.

Com a mesma percepção acerca da gravidade da violência psicológica, Silva e Alves (2016) reúnem fundamentos científicos para sustentar a caracterização desse tipo de violência enquanto lesão corporal, haja vista o comprometimento significativo da saúde da vítima em uma perspectiva generalizada, o que se coaduna perfeitamente com o enunciado do art. 129 do Código Penal Brasileiro. Assim, a violência psicológica, manifestação de violência de gênero prevista na Lei Maria da Penha, deve ser entendida como vetor de lesão corporal, que prejudica sensivelmente a saúde das vítimas na medida em que interfere diretamente em sua integridade psicológica.

Observa-se, também, no referido crime, a prática de violência moral, à proporção que a exposição da intimidade feminina em ambientes de socialização presencial e/ou virtual implica em escândalos e julgamentos de reprovação social do comportamento permissivo e, supostamente, ousado assumido pelas vítimas, por serem mulheres, comprometendo, desse modo, a reputação mantida na perspectiva social e a autoestima alimentada no âmbito individual.

Igualmente, observa-se a possibilidade de cometimento de crimes de violência sexual à medida que fotos, vídeos, mensagens e áudios produzidos em um contexto íntimo podem subsidiar ameaças e imposição de atos sexuais forçados, figura doutrinária reconhecida no Brasil enquanto estupro virtual.

Outra possibilidade de violência de gênero presente na divulgação não autorizada da intimidade feminina é a violência patrimonial, haja vista a necessidade de a vítima custear despesas imprevistas após a divulgação da sua sexualidade, como mudança de endereços profissionais e residenciais; mudança de nome e alteração da aparência; despesas com tratamentos médicos e psicológicos, e custos com a manutenção de processos judiciais decorrentes do crime. 
Considerando-se a multiplicidade de violências de gênero perpetradas no contexto da exposição não autorizada da sexualidade feminina e as suas gravíssimas implicações para vida das vítimas, a aplicação da Lei Maria da Penha é medida que se impõe, implicando a fixação de competência para conhecimento e julgamento desses delitos nas varas de violência doméstica.

Quanto ao significado e abrangência da violência combatida pela Lei Maria da Penha, Maria Berenice Dias (2008) pontua que, a partir da vigência da Lei 11.340/06 no Brasil, o crime de violência doméstica se diferencia, significativamente, dos tipos estabelecidos no Código Penal, haja vista a delimitação precisa da conduta de acordo com os seguintes vetores: a) violência é qualquer ação ou omissão baseada no gênero que lhe cause morte, lesão, sofrimento físico, sexual ou patrimonial (art. $\left.5^{\circ}\right)$; b) constituem espaços e ou contextos onde o agir configura violência doméstica o âmbito da unidade doméstica, da família e qualquer relação de afeto (art. $5^{\circ}, \mathrm{I}, \mathrm{II}, \mathrm{III}$ ); c) constituem condutas violentas as agressões físicas, psicológicas, sexuais, patrimoniais e morais previstas no art. $7^{\circ}$ da referida lei.

De acordo com o disposto no art. $5^{\circ}$ da referida legislação pátria, "configura-se como violência doméstica e familiar contra a mulher qualquer ação ou omissão baseada no gênero que lhe cause morte, lesão, sofrimento físico, sexual ou psicológico e dano moral ou patrimonial". Intentando delimitar de forma objetiva os contextos em que se pode considerar a prática da violência reprimida legalmente, a Lei Maria da Penha traça os seguintes eixos:

I - no âmbito da unidade doméstica, compreendida como o espaço de convívio permanente de pessoas, com ou sem vínculo familiar, inclusive as esporadicamente agregadas; II - no âmbito da família, compreendida como a comunidade formada por indivíduos que são ou se consideram aparentados, unidos por laços naturais, por afinidade ou por vontade expressa; III - em qualquer relação íntima de afeto, na qual o agressor conviva ou tenha convivido com a ofendida, independentemente de coabitação (Art. $5^{\circ}$ ). (BRASIL, 2006).

Consequentemente, a aplicação da Lei Maria da Penha à pornografia de vingança fica condicionada à observação de algum desses âmbitos na ocorrência do caso concreto, não havendo tal subsunção quando a violência não for fundada no gênero, tampouco observável nos âmbitos doméstico, familiar e ou afetivo.

Não obstante tais limitações, aparentemente apresentadas do ponto de vista jurídico, é possível afirmar cientificamente que a Lei Maria da Penha se aplica na quase totalidade das ocorrências envolvendo a pornografia de vingança. Isto porque, independentemente das conjunturas que subsidiem a prática da conduta, o gênero sempre será um elemento predominante, que confere um estigma social e interindividual às mulheres cuja sexualidade foi exposta e dá ao agressor a certeza de que a exposição é meio idônea para provocar dor e sofrimento alheios. Aliás, o gênero é um elemento que condiciona, significativamente, a prática de crimes contra as mulheres na internet, o que se repete no caso da pornografia de vingança.

Sujeitas ao assédio, perseguição e violência de conhecidos e estranhos, em ambientes domésticos ou não, as mulheres constituem um grupo significativo entre as vítimas de crimes praticados na internet. Corroborando esse raciocínio, o relatório Vozes dos espaços digitais: violência contra a mulher relacionada à tecnologia é relevante, do ponto de vista científico, à proporção que demonstra como as diferentes tecnologias da informação podem ser potencialmente usadas para perpetrar a violência de gênero (FIALOVA; FASCENDINI, 2012).

O mesmo estudo indica ainda que as mulheres sofrem cotidianamente com o assédio na internet, violação que pode se apresentar em fóruns de discussões online, quando estranhos constrangem essas vítimas a externalizar a sua sexualidade com a finalidade de forçar a sobrevivência de amizades íntimas ou paqueras (FIALOVA; FASCENDINI, 2012).

Além disso, o laço afetivo entre vítima e agressor de pornografia de vingança é um dado empírico largamente observado nos estudos científicos nacionais, internacionais e regionais que já foram produzidos sobre essa temática. A esse respeito, o relatório Sexting no Brasil evidencia que parcela significativa do conteúdo íntimo que circula nas redes é enviado por mulheres a seus pares afetivos, como prova de confiança.

Demonstrando claramente a influência das diferenciações de gênero sobre as percepções e comportamentos masculinos e femininos na disposição da intimidade nas redes, o relatório Sexting no 
Brasil (ECGLOBAL [...], 2015) constitui um documento de imensurável importância acerca dos valores juvenis no meio virtual.

Preliminarmente, o referido estudo conceitua o termo sexting como a junção de palavras inglesas sex (sexo) e texting (mensagens de texto), prática que consiste no envio de mensagens com conteúdo sexual, podendo compreender fotos e vídeos, produzidos pela pessoa que os compartilha ou por terceiros.

Entre as principais motivações para o envio de mensagens, fotos ou vídeos envolvendo nudez própria e de terceiros, a pesquisa apontou que a divulgação de conteúdo de nudez própria é explicada, principalmente, pelo desejo de presentear o namorado (47\%), com finalidade de paquera (32\%) e ainda para chamar a atenção (31\%). Já a divulgação de conteúdo de nudez envolvendo terceiros é utilizada como resposta $(42 \%)$, piada (34\%), atendimento a pedidos $(29 \%)$ e reciprocidade com pessoas que também socializam esse tipo de material $(23 \%)$.

Nessa discussão, se observa a incidência majoritária de questões afetivas condicionando o envio de conteúdo íntimo próprio, bem como a expressividade do elemento "resposta" e "piada" no compartilhamento com terceiros (ECGLOBAL [...], 2015).

Do ponto de vista regional, dissertação de mestrado realizada na Universidade Federal do Maranhão (PINHEIRO, 2018) investigou a totalidade dos processos judiciais envolvendo pornografia de vingança no referido estado, implicando na análise manual de 7.601 autos físicos, entre os quais 20 tratavam explicitamente da temática. Sobre o gênero enquanto elemento empiricamente observável na conduta, a pesquisa chegou às seguintes conclusões:

Uma avaliação das categorias relacionadas com o sexo de vítimas e agressores apontou para a predominância das mulheres no pólo passivo da conduta, bem como dos homens do pólo ativo, sendo assim, a perpetração majoritária de pornografia de vingança por homens em face de mulheres é um achado empírico que corrobora as afirmações estudadas no âmbito da literatura científica internacional (PINHEIRO, 2018, p. 134).

O mesmo estudo destacou, ainda, a larga incidência do elemento afetivo na totalidade dos processos que compuseram a amostra estudada:

Quanto à responsabilidade pela exposição íntima, A totalidade dos processos analisados, tanto nos juizados especiais criminais, quanto na vara especializada em violência doméstica, revelou que as exposições íntimas não autorizadas da intimidade feminina aconteceram em, cem por cento dos casos, a partir de condutas desenvolvidas por pessoas que tinham ou tiveram, à época dos fatos, algum vínculo afetivo e ou sexual com as vítimas.

Chamou a atenção, na pesquisa, a clareza do contexto de gênero em que se praticou a violência, o que é relatado de forma cristalina por todas as vítimas na instância policial, seja na delegacia de crimes cibernéticos, seja na delegacia da mulher, evidenciando-se, na totalidade dos casos, a correspondência entre o agressor e as figuras do marido, pai dos filhos, ex-marido, namorado, exnamorado, companheiro, ex-cunhado, ex-companheiro ou ainda pessoa de uma relacionamento afetivo e ou sexual não especificado (PINHEIRO, 2018, p. 134).

Ante o exposto, os dados empíricos evidenciaram, do ponto de vista internacional, nacional e regional, a altíssima probabilidade de o fenômeno da pornografia de vingança estar associado ao elemento gênero e, nesse contexto, a vínculos afetivos e ou sexuais entre vítimas e agressores, justificando, portanto, a aplicação da Lei Maria da Penha.

Não obstante a desnecessidade de criação de um novo dispositivo jurídico para disciplina da pornografia de vingança em razão da autossuficiência da Lei Maria da Penha para fazer frente à complexidade do fenômeno, no ano de 2018, foi promulgada no Brasil a Lei 13.718/2018, conhecida popularmente como Lei de Importunação sexual.

Essa norma altera o Código Penal para tipificar os crimes de importunação sexual, definidos como crimes que lesem o bem jurídico da liberdade sexual, e divulgação de cena de estupro. No contexto da lei, a pornografia de vingança pode ser enquadrada no art. 218-C, que estabelece o seguinte: 
Art. 218-C. Oferecer, trocar, disponibilizar, transmitir, vender ou expor à venda, distribuir, publicar ou divulgar, por qualquer meio - inclusive por meio de comunicação de massa ou sistema de informática ou telemática -, fotografia, vídeo ou outro registro audiovisual que contenha cena de estupro ou de estupro de vulnerável ou que faça apologia ou induza a sua prática, ou, sem o consentimento da vítima, cena de sexo, nudez ou pornografia:

Pena - reclusão, de 1 (um) a 5 (cinco) anos, se o fato não constitui crime mais grave.

\section{Aumento de pena}

$\S 1^{\circ}$ A pena é aumentada de $1 / 3$ (um terço) a $2 / 3$ (dois terços) se o crime é praticado por agente que mantém ou tenha mantido relação íntima de afeto com a vítima ou com o fim de vingança ou humilhação. (BRASIL, 2018, grifo nosso).

No dispositivo em comento, observa-se que o legislador se referiu explicitamente ao fenômeno da pornografia de vingança ao reprimir a exposição não autorizada da intimidade e/ou sexualidade alheia, conduta agravada quando praticada em um contexto afetivo com a finalidade de vingança ou humilhação da vítima. Muito embora a redação legislativa se mostre adequada, a norma por si só não é suficiente para a compreensão da pornografia de vingança.

Isto porque aborda o crime em um viés exclusivamente punitivista, deixando de lado as diversas modalidades de violência de gênero praticadas contra as vítimas e já previstas na Lei Maria da Penha. Sendo assim, uma melhor exegese do fenômeno jurídico pressupõe a aplicação subsidiária do art. 218-C do Código Penal, inserido pela Lei de Importunação sexual, combinada com a Lei Maria da Penha, que cataloga as diferentes formas de violência envolvidas, bem como estabelece um processo penal protetivo para vítimas e potencialmente restaurativo para agressores.

\section{A equiparação às prostitutas e os reflexos emocionais, sociais, morais e institucionais para as vítimas cuja intimidade é exposta}

O pavor das vítimas ante as ameaças de divulgação do seu conteúdo íntimo e o constrangimento diante do cumprimento de tais ameaças deve-se à inevitável repercussão negativa da sexualidade feminina na esfera pública, tanto nas redes sociais como nos espaços de relacionamento presencial. Isto ocorre por conta da vigência de discursos de naturalização do comportamento do agressor e reprovação da conduta supostamente permissiva/ousada exibida pela vítima, que, exercendo a sua sexualidade, além dos limites sociais rígidos que conformam a sexualidade feminina, está sujeita a um linchamento moral.

Esse julgamento normalmente é contextualizado com a comparação do desempenho sexual feminino exposto ao comportamento socialmente condenado das prostitutas, figuras públicas estereotipadas pelo suposto desprendimento de valores morais rígidos que deveriam restringir os comportamentos exibidos pelo gênero feminino, sugerindo, assim, a sujeição aos fetiches de todos os homens que se comprometem a pagar pelos seus serviços sexuais.

No contrato de prostituição, observa-se o fenômeno cultural de erotização da violência sexual, conforme pontua Naomi Wolf (1992). Conferindo-se especial atenção à dominação exercida através da imposição do ato sexual, acompanhada por fantasias sexuais que implicam em comportamentos de violência, frequentemente associados ao exercício sexual dito "criativo". A interpretação do sexo pelas diferentes culturas, desde os tempos remotos da civilização, concede ao homem o status de dever ser ele o ativo em busca da exploração do corpo feminino, passivo em essência, devendo servir apenas como fonte de prazer e fetiches (WOLF, 1992).

Descortinando os contornos sociais pejorativos atrelados à figura da prostituta, Naomi Wolf observa ainda a existência de um "mito da beleza", espécie de mecanismo de representação que permite utilizar as imagens do belo contra as mulheres. Atualizado conforme os diferentes períodos históricos, o mito da beleza é instrumento moderno e simbólico de dominação masculina, que, moldando o comportamento, aparência e vontades femininas a modelos pré-constituídos, reforça a submissão das mulheres a estigmas de beleza propositalmente criados para garantir o seu controle em diversos aspectos, como restrições de 
tempo e dinheiro investidos em rituais de beleza, restrições alimentares e de roupas e sapatos que limitam sua mobilidade (WOLF, 1992).

Nesse sentido, o mito da beleza torna, propositalmente, o sadomasoquismo e a pornografia belos, relacionando profundamente um ao outro, de forma a imprimir no imaginário coletivo que as mulheres, em especial as prostitutas, gostam de ser forçadas e violentadas e que o estupro e a violência sexual são modernos, elegantes e bonitos (WOLF, 1992). De acordo com a referida autora, essa fabricação dos sentidos de ser homem enquanto agente da violência sexual e o ser mulher enquanto sujeito passivo dessa é instrumentalizada por estratégias de comunicação e marketing que naturalizam a prática de violência, imprimindo, em agressores e vítimas, a predisposição para o desenvolvimento de comportamentos condizentes com a naturalização das agressões.

Essas percepções, inseridas em uma ordem social reconhecidamente masculina, são claramente identificadas quando da exposição não autorizada da intimidade feminina. Assim, a vítima é apresentada ao grande público como uma prostituta cuja graciosidade reside na predisposição ao sofrimento advindo dos fetiches de um número infinito de homens. Expressando o sentimento de posse e controle exercido pelo homem sobre o comportamento, autonomia, corpo e intimidade das mulheres, a prática é uma demonstração da dominação masculina já observada em espaços presenciais nos ambientes virtuais.

A perda de controle sobre a vida profissional, afetiva e familiar experimentada por essas vítimas somase à vulnerabilidade perante ataques de estranhos que, associando a sexualidade feminina à oferta de serviços de prostituição, contribuem para agravar o constrangimento e sofrimento das mulheres vitimizadas. Conferindo atenção aos sentimentos experimentados pelas vítimas de pornografia de vingança, estudo constatou que o sofrimento é constante na vida das mulheres cuja sexualidade foi exposta, figurando em 93\% dos relatos colhidos (FRANKS, 2015).

Identificando especialmente os prejuízos psicológicos, morais e sociais experimentados pelas vítimas, pesquisa de iniciativa da Cyber Civil Rights indicou que $42 \%$ recorreram a serviços psicológicos, $82 \%$ relataram prejuízo significativo nas áreas sociais e ocupacionais, $54 \%$ relataram dificuldade de se dedicar ao trabalho e à escola, $13 \%$ relatam dificuldades de conseguir um emprego ou entrar na faculdade, $26 \%$ tiveram que se afastar do trabalho ou sair da escola no meio do semestre, $55 \%$ temem que o ocorrido traga consequências para a reputação profissional no futuro, $57 \%$ têm receio de a exposição afetar as suas possibilidades de promoção no futuro, $52 \%$ sentem que a exposição é um fato que precisa ser ocultado diante de um potencial empregador em uma entrevista, $42 \%$ tiveram que explicar a situação aos supervisores profissionais ou acadêmicos (FRANKS, 2015).

Finalmente, a pesquisa realizada pela organização Cyber Civil Rights constatou que $51 \%$ das vítimas de pornografia de vingança apresentaram pensamentos suicidas após a disponibilização do conteúdo íntimo (FRANKS, 2015).

Desacreditando no valor de si próprias, as mulheres cuja sexualidade foi exposta reconhecem como legítima a dominação masculina exercida pelo agressor e ratificada pelos discursos sociais, haja vista a formação sexista que condiciona a afirmação da autoestima feminina à aprovação da sua conduta das mulheres na sociedade, incluindo-se no sistema de justiça. Assim, o valor social da mulher não é definido pelas atividades singulares desempenhadas por essa, mas sim pela reputação mantida junto aos seus pares, medida que pode decrescer exponencialmente se a mercadoria se torna demasiadamente comum (BEAUVOIR, 1960).

De acordo com Bourdieu (2007), a dominação simbólica transforma as vítimas em objetos, utensílios sujeitos à apreciação de terceiros, dos quais provém uma dependência simbólica que coloca as mulheres em estado de insegurança permanente. Essa dependência emocional, fomentada no curso dos processos culturais, orienta a existência feminina para outrem, impondo-lhes a autodepreciação, a incorporação do julgamento social e a rejeição à própria identidade (BOURDIEU, 2007).

Essa colocação das vítimas no lócus cultural ocupado pelas garotas de programa, caracterizado pela marginalidade social em essência, implica na valoração do seu corpo em detrimento dos seus gestos, seus pensamentos, seus anseios e das violações sofridas, o que despersonifica a mulher enquanto ente humano 
e existencial, reduzindo-a um objeto disponível para apreciação e exploração dos homens e condenação social por outras mulheres.

Tal invisibilidade da violência intensa perpetrada contra mulheres quando possuem sua intimidade exposta e da natureza humana das vítimas é perceptível até mesmo nas decisões jurisdicionais, refletindo a ratificação da dominação masculina na esfera institucional, como se pode observar nesse julgado do Tribunal de Justiça do Rio de Janeiro:

\begin{abstract}
[...] Só mulher feia pode se sentir humilhada, constrangida, vexada em ver seu corpo desnudo estampado em jornais ou em revistas. As bonitas, não. Fosse a autora uma mulher feia, gorda, cheia de estrias, de celulite, de culote e de pelancas, a publicação de sua fotografia desnuda- ou quaseem jornal de grande circulação, certamente lhe acarretaria um grande vexame, muita humilhação, constrangimento enorme, sofrimento sem conta, a justificar- aí sim- o seu pedido de indenização de dano moral, a lhe servir de lenitivo para o mal sofrido (RIO DE JANEIRO, 1999).
\end{abstract}

Acrescentando mais termos a essa discussão acerca da depreciação fundada em uma dominação masculina, tese perfeitamente aplicável à divulgação não autorizada da intimidade feminina em ambientes presenciais e virtuais, Simone de Beauvoir corrobora esse raciocínio, pontuando que a lógica do gênero imprime majoritariamente nas mulheres a sujeição e o receio da reprovação social (BEAUVOIR, 1960).

Considerando que a educação tradicional feminina, baseada em binarismos sexistas, ensina desde cedo a negação da sua autonomia e identidade, as mulheres não constituem sujeitos responsáveis pela sua própria existência, porque existem apenas para outros (BEAUVOIR, 1960). Nesse contexto, ao ser considerada uma prostituta e ser tratada como tal por pessoas próximas e estranhas, suscita nas vítimas a corrosão de todo a estima e respeito devidos pela sociedade, havendo a negação do sentimento de pertencimento social e de autovalorização.

\title{
4 Perspectivas de disposição e exposição da sexualidade feminina e seus diferentes enquadramentos na esfera criminal
}

O que rege a conduta da divulgação de fotos íntimas, seja no contexto da sextorsão, seja no contexto de pornografia de vingança, é o estabelecimento de relações de poder. Assim, mulher vítima é, simbolicamente, colocada em posição de submissão às deliberações do seu agressor, que pode utilizar as coerções para obter vantagens patrimoniais e ou sexuais, bem como para exercer o controle constante de todos os seus passos, destruindo-a ou comprometendo-a socialmente.

Nessa perspectiva, independentemente das motivações que expliquem as ameaças de compartilhamento ou a efetiva divulgação da sexualidade feminina na esfera pública, o gênero é um elemento central, haja vista sua incidência no pólo ativo do crime, majoritariamente representado pelos homens, e do polo passivo, normalmente ocupado por mulheres.

Além disso, o gênero é um fator que explica todos os julgamentos sociais negativos impostos às mulheres cuja intimidade foi publicizada e o medo delas ante o compartilhamento do material, haja vista a consciência da divisão cultural desigual de papéis sociais entre os sexos e as consequências destrutivas da exposição, como a assunção de culpa feminina ante o ocorrido.

Considere-se que os homens também podem ser vítimas da exposição não autorizada da sua sexualidade, no entanto, os binarismos de gênero são aptos a minorar os eventuais prejuízos sofridos pela exposição, convertendo-os em demonstração pública da virilidade e aclamação entre os outros homens. Corroborando esse raciocínio, o relatório Sexting no Brasil concluiu que, mesmo gerando problemas pessoais, a maior parte dos homens $(60 \%)$ sustentou que continuaria enviando conteúdo sexual próprio, enquanto apenas $15 \%$ das mulheres que já tiveram problemas pessoais decorrentes de envio de sexting continuariam enviando conteúdos sexuais próprios (ECGLOBAL, 2015).

Portanto, a exposição não autorizada da sexualidade é uma prática enraizada no gênero, motivada e naturalizada pelo simples pertencimento de alguém ao sexo feminino, o que se coaduna com a definição de crime de gênero trazida pela Lei 13.104/2015, conhecida como Lei do Feminicídio. 


\section{Feminicídio}

$\mathrm{VI}$ - contra a mulher por razões da condição de sexo feminino:

$\S 2^{\circ}$ - A Considera-se que há razões de condição de sexo feminino quando o crime envolve: I - Violência doméstica e familiar; II - Menosprezo ou discriminação à condição de mulher. (BRASIL, 2015).

Tendo o gênero enquanto denominador comum, a exposição não autorizada da intimidade feminina na internet pode assumir diferentes nuanças em sede de Direito Penal, chegando a constituir crimes e consequências jurídicas diferentes, sendo o menosprezo da condição feminina um elemento presente e fundamental de ser considerado em todos eles.

Nessa discussão, é possível que o mesmo fenômeno da violência doméstica e familiar de gênero se apresente através de tipos penais diferentes. Damásio de Jesus (2010) pontua acertadamente que a Lei Maria da Penha, até pela sua própria natureza penal abrangente, não traz tipos penais, mas formas de violência, nas quais é possível enquadrar crimes autônomos, como injúria, ameaça e constrangimento ilegal, entre outros.

Então, a exposição não autorizada da intimidade feminina, constituindo uma ou mais modalidades de violência previstas na Lei Maria da Penha, pode se destrinchar em vários tipos penais previstos na legislação criminal brasileira.

\subsection{Sextorsão}

Tendo posse de material íntimo cuja divulgação que pode causar constrangimento e devastação da vida da vítima em todas as suas esferas, os agressores frequentemente utilizam esse conteúdo para fazer chantagens e/ou para obter vantagens sexuais e/ou sexuais ilícitas, conduta paulatinamente denominada pela doutrina como sextorsão. Descortinando a etimologia do termo, há autores que pontuam que a expressão consiste na aglutinação das palavras sexo e extorsão, sugerindo-se a situação em que uma relação de poder subsidia a exigência e obtenção de vantagens patrimoniais e sexuais (SYDOW; CASTRO, 2015).

Desse modo, a sextorsão constitui a chantagem e coerção psicológica destinada a manter as vítimas, predominantemente do sexo feminino, sob controle constante de gestos e emoções, imprimindo nelas o medo de ter a sua intimidade, exercida para além dos limites rígidos dos estereótipos morais impostos apenas ao gênero feminino, transposta para o entretenimento público, dimensão permeada pela divisão cultural desigual de papéis sociais entre os sexos.

\footnotetext{
A sextorsão encontra na era tecnológica um imenso propulsor da coerção psicológica, que beneficia os autores e apavora as vítimas, uma vez que o potencial de difusão e de danos à intimidade é incalculável. Dessa forma, tanto a vítima que na sextorsion conceitual cede ao abuso de poder e se submete à prática sexual, sendo, então, fotografada ou filmada, permanecerá nas mãos do explorador, quanto a vítima da sextorsion das relações cotidianas será mantida sob permanente controle. Importante também dizer que a sextorsão, embora se estenda a homens e mulheres, encontra nas vítimas do sexo feminino seus principais alvos. A abordagem da herança histórico-cultural e dos estereótipos sobre masculinidade e feminilidade que conduzem à discriminação merece artigo específico, mas não se pode encerrar este sem reconhecer que a inegável prevalência da sextorsion contra as mulheres nada mais é do que uma inter-relação da disparidade de poder entre os gêneros, e a disparidade de poder entre os detentores de autoridade ou hierarquia e seus dependentes ou subordinados. É o resultado de uma dupla situação de dominação (SYDOW; CASTRO, 2015, p. 8).
}

Consciente do patriarcado, machismo e sexismo que subsistem na maior parte das sociedades ocidentais, não obstante a vigência de um discurso jurídico que pugna pela igualdade de gêneros, a vítima da sextorsão encontra-se em posição de elevada vulnerabilidade, haja vista a eminência de sofrer mal irreparável e a impotência diante dessa possibilidade. 


\subsubsection{Extorsão}

A coerção psicológica voltada à obtenção de vantagens patrimoniais ante a possibilidade de exposição íntima na internet está relacionada ao crime de extorsão, tipificado no art. 158 do Código Penal brasileiro'. Ponderando sobre as características dessa figura típica em uma acepção ampla, Bitencourt (2012) observa que o bem jurídico tutelado pelo tipo penal ultrapassa a percepção do patrimônio da vítima restrita à posse e propriedade, estendendo-se à liberdade individual e integridade física e psíquica da vítima.

Conforme muito bem pontuado pelo autor, a extorsão é um crime complexo, que ameaça significativamente bens jurídicos, como a liberdade individual, o patrimônio e a integridade física e psíquica das vítimas. Sendo assim, a extorsão pode estar associada com resultados de variadas ordens, implicando desde a materialização de um constrangimento físico e/ou emocional até a obtenção de uma vantagem econômica indevida (BITENCOURT, 2012).

Consoante entendimento jurisprudencial já solidificado no âmbito do Superior Tribunal de Justiça, a configuração do crime de extorsão não exige a efetiva obtenção da vantagem econômica, bastando que o sujeito ativo constranja a vítima de modo a consegui-la para que se observe a prática do ilícito penal (BRASIL, 2016).

De acordo com os estudos trazidos no trabalho monográfico de Vitória Buzzi (2016), o Judiciário tem enquadrado criminalmente como extorsão contextos em que o ex-companheiro da vítima lhe exige algum tipo de vantagem econômica sob pena de divulgar o material íntimo que está em seu poder e, sabidamente, trará repercussões negativas na esfera pública.

\subsubsection{Constrangimento ilegal e ameaças}

Além de utilizar o conteúdo íntimo como subsídio para a prática de ameaças e de outros crimes que lesem o patrimônio das vítimas, o agressor também pode fazer uso de chantagens e, no contexto, de condutas que firam a liberdade individual e pessoal da pessoa sob controle.

Definindo com acuidade os contornos dessa liberdade protegida pela legislação criminal, Damásio de Jesus (2013) preceitua que o conteúdo jurídico desse bem está umbilicalmente relacionado à tomada de decisões, adoção de condutas, autodeterminação, bem como a avaliação da conveniência e oportunidade das ações, livres de coação ou constrangimento e dentro da liberdade de pensamento, religiosa, de ofício e/ou política.

No caso do crime de ameaça, que pode ser meio para execução de outros como o constrangimento legal, por exemplo, perturba-se a tranquilidade e a paz interior da vítima, abalada ante o medo, a insegurança e o desequilíbrio psíquico e emocional. Desse modo, a liberdade, enquanto bem jurídico ofendido por esses crimes, corresponde às condições ideais para que as vítimas elaborem seus pensamentos e possam concretizá-los destemidamente (BITENCOURT, 2012).

Tal liberdade, tutelada pelo Código Penal, pode ter natureza física e/ou psicológica, sendo lesada quando a vítima se vê obrigada a agir conforme a vontade do sujeito ativo do crime ante o medo de ter sua intimidade exposta publicamente.

\footnotetext{
As vítimas expostas a esse tipo de violência sofrem uma expressiva carga emocional e social, ficando sujeitas a situações constrangedoras e até mesmo ameaçadoras. Como resultado dessa exposição indevida, as vítimas comumente são perseguidas e ameaçadas, podendo muitas vezes ser obrigadas a abandonar suas vidas 'normais'. Rendendo-se assim, ao intento do ofensor (KOHLRAUSCH, 2017, p. 31).
}

"Art. 158 - Constranger alguém, mediante violência ou grave ameaça, e com o intuito de obter para si ou para outrem indevida vantagem econômica, a fazer, tolerar que se faça ou deixar de fazer alguma coisa: [...].” 
Entre as condutas que colocam em risco esse direito encontram-se os crimes de ameaça e constrangimento ilegal. ${ }^{2}$ Ambos podem ser praticados sob a forma de sextorsão, que consiste na exigência de que as vítimas adotem determinadas condutas através do recurso à grave ameaça e violência. No contexto da sextorsão, esse constrangimento pode ter variadas finalidades como obrigar a vítima à continuidade de uma relação não desejada por aquela, desencorajar denúncias de abusos e violências, impor ao sujeito passivo do crime a adoção de determinados comportamentos, como exclusão de pessoas do seu círculo de amizades, demonstrações públicas de afeto, retratação ante queixas relacionadas às agressões sofridas, entre outros.

Diante de todo o exposto, Mary Anne Franks (2015) pontua que ameaça de exposição da sexualidade feminina desempenha um papel importante na prática e manutenção da violência de gênero, haja vista a adoção de condutas que afetam profundamente a saúde psíquica e fisiológica das vítimas e o silenciamento desses comportamentos criminosos através da imposição do medo de ter a intimidade exposta.

\subsubsection{Estupro virtual}

De posse do material íntimo, o agressor também pode utilizar o conteúdo para fazer ameaças e/ou constranger as vítimas a praticar condutas sexuais forçadas, ferindo, dessa forma, a sua liberdade sexual, que é entendida como a faculdade que o ser humano possui de escolher livremente o(a) seu(sua) parceiro(a) sexual, além da forma e quando deseja pôr em exercício sua sexualidade. Dessa forma, a liberdade e dignidade sexual são encorpadas pelo direito inalienável de escolha (BITENCOURT, 2018).

Aprofundando os contornos dessa discussão, Damásio de Jesus (2013) acrescenta que a lei penal protege a livre escolha ou consentimento nas relações sexuais, garantindo às pessoas a disposição do seu próprio corpo, selecionando a seu critério parceiros sexuais e momentos para a prática de atividade sexual. O ilustre penalista afirma ainda que esse bem jurídico pode ser ofendido através de violência física ou moral. Entre os crimes que lesam a dignidade sexual e podem estar associados à sextorsão, destacase o estupro ${ }^{3}$.

Dada a abertura hermenêutica da expressão "outro ato libidinoso", o enquadramento de uma conduta enquanto estupro fica condicionado à exegese dos operadores do Direito, que devem, utilizando parâmetros de proporcionalidade, verificar se a conduta em questão foi apta para ferir a dignidade sexual das vítimas.

Diante do ineditismo da conduta no arcabouço do Direito Penal contemporâneo, é comum se observar variados esforços doutrinários no sentido de se definir os contornos exatos da conduta. Autores como Mocho (2016) defendem que o estupro virtual consiste na própria violação da intimidade das mulheres, sendo meio utilizado pelos agressores para angariar a prática de relações sexuais não desejadas pelas vítimas e/ou a continuidade em uma relação abusiva.

Observa-se a possibilidade de violência sexual à medida que fotos, vídeos, mensagens e áudios produzidos em um contexto íntimo podem subsidiar ameaças e imposição de atos sexuais forçados, fato reconhecido na primeira decisão jurisdicional de estupro virtual do Brasil, em que o juiz piauiense Luiz de Moura Correia vislumbrou a incidência do art. 213 do Código Penal (constranger alguém, mediante violência ou grave ameaça, a ter conjunção carnal ou a praticar ou permitir que com ele se pratique outro ato libidinoso).

No caso concreto, o agressor alimentava um perfil falso no facebook, no qual ameaçava divulgar fotos íntimas da vítima caso essa se recusasse a enviar mais conteúdo sexual seu para ele. Entre as principais coações feitas sob a vítima, o agressor exigiu que essa enviasse fotos se masturbando e introduzindo objetos em sua genitália, conduta entendida pelo magistrado enquanto estupro, haja vista a coação moral irresistível forçando a prática de ato libidinoso pela ofendida (BITENCOURT, 2018).

\footnotetext{
Constrangimento ilegal - "Art. 146 - Constranger alguém, mediante violência ou grave ameaça, ou depois de Ihe haver reduzido, por qualquer outro meio, a capacidade de resistência, a não fazer o que a lei permite, ou a fazer o que ela não manda.".

3 Estupro - "Art. 213. Constranger alguém, mediante violência ou grave ameaça, a ter conjunção carnal ou a praticar ou permitir que com ele se pratique outro ato libidinoso.".
} 
Diante de todo o exposto, observa-se que a sextorsão é um fenômeno que admite adequação típica plural, existindo sempre que uma relação de poder seja o contexto para a prática de estupro, constrangimento ilegal ou extorsão com base na ameaça de divulgar conteúdo íntimo feminino.

\subsection{Represália ante traições ou términos afetivos: pornografia de vingança}

A exposição não autorizada da sexualidade feminina como forma de represália ao fim de relacionamentos afetivos e/ou sexuais ou infidelidade constitui motivação muito recorrente e exemplifica ajustamento da conduta do agressor a uma ordem masculina, invisibilizada por naturalização cultural e sexista, inclusive no âmbito do sistema de justiça, imprimindo na formação dele a necessidade de recurso à violência em situações de vingança. Essa conjuntura também fabrica, no meio social, expectativas para as reações ideais de um homem inconformado frente a uma rejeição feminina, inseguro e com autoestima comprometida, como vingar-se, intentando supostamente recuperar no meio social a honra minorada pela decisão feminina do término ou do exercício de sua sexualidade com outro homem.

De acordo com Varela (2008), desde os tempos primitivos, a educação masculina ensina precocemente a lançar mão da agressão como forma privilegiada de resolver conflitos. Assim, a história dos homens é uma história de conquista, competitividade, autoridade, resistência e violência, valores que são, culturalmente, associados à noção ideal de masculinidade, e imprimem nos sujeitos a falsa percepção de que as condutas impetuosas são instintivas e não apreendidas, o que legitima socialmente a prática de variadas modalidades de violência.

Desse modo, a perpetração da violência é uma espécie de código moral socialmente imposto aos homens, na lógica dos binarismos de gênero, considerando que os significados da virilidade aclamada no comportamento masculino ultrapassam a capacidade reprodutiva, alcançando a aptidão para o exercício da violência, especialmente em situação de vingança. A impetuosidade, agressividade e violência são, desse modo, símbolos que permitem o crescimento da honra e distinção masculinas na esfera pública.

Nesse sentido, observa-se o conteúdo da letra da música "vou jogar na internet", lançamento da dupla sertaneja brasileira Marx e Mariano, que foi alvo de críticas ferrenhas na internet por incitar, humorizar e naturalizar a violência de gênero através da prática de pornografia de vingança. No contexto da canção, o eu lírico utilizou um recurso ardil para se vingar da sua ex-parceira sexual, registrando momentos íntimos do casal sem que ela consentisse a filmagem ou autorizasse a publicação. "[...] E sem que você percebesse eu gravei de nós dois um vídeo de amor [...] Eu vou jogar na internet; eu Vou Jogar na Internet; nem que você me processe; eu quero ver a sua cara quando alguém te mostrar; quero ver você dizer que não me conhece [...]." (STREIT, 2017).

A partir da letra da música, observa-se o claro intento do eu lírico no sentido de vingar-se da vítima, sujeitando-a, para tanto, ao constrangimento público, que sabidamente abalaria as suas estruturas emocionais em decorrência do processo de corrosão da sua honra no espaço público, elemento imprescindível para o reconhecimento do valor feminino no contexto das diferenciações de gênero. Além disso, explicita desdém frente ao sistema de justiça, reafirmando a crença social na impunidade a esse tipo de conduta.

Observe-se o quanto a explicitação na crença da impunidade de quem comete esse tipo de delito ante as instituições do sistema de justiça estimula a prática de tais condutas, haja vista a certeza de que o custo-benefício da vingança supera os infortúnios implicados por uma eventual demanda judicial movida pela vítima ou pelo Estado em face do agressor. Fica clara, desse modo, a naturalização do recurso à violência de gênero no âmbito das sociedades machistas, haja vista o escancaramento de práticas nocivas à dignidade e saúde mental da mulher nos espaços públicos e privados, o que é fidedignamente retratado pela arte, conforme é observado na referida composição, produzida para o consumo em massa.

Assimilada a partir de discursos de gênero naturalizados no seio da sociedade machista, a socialização da vingança enquanto mecanismo de recuperação da honra ferida, especialmente em casos de traição, está presente na percepção de homens pertencentes a qualquer faixa etária. A dissertação de mestrado desenvolvida pela antropóloga Isabela Rangel Petrosillo (2016) descortinou os discursos de gênero 
produzidos por adolescentes em contextos de escolas públicas e privadas, evidenciando os seguintes achados empíricos:

Aqui se apresenta a fragilidade desse modelo de masculinidade, que apenas concebe que o homem seja o agente da traição e não o ser traído. Enviar a foto que possuía é mostrar que detém poder sobre aquele corpo exposto. Durante as narrativas das jovens, a fala de alguns rapazes aparece em tom ameaçador: 'Eu acabo com você, se...'; 'Se você não me mandar uma foto sua...'. Nesse quadro, a reputação feminina fica submissa aos desígnios dos rapazes por meio de práticas de coerção (PETROSILLO, 2016, p. 119).

Essa legitimação da vingança pública masculina ante a frustração com o comportamento feminino destoante dos padrões sexistas de gênero, que impõem passividade, anulação da autonomia e continuidade em relacionamentos abusivos às mulheres, não é um fenômeno novo, considerando a sua emergência desde os primórdios das civilizações.

Tal naturalização da vingança, seja por motivo de traição, seja por inconformidade do companheiro ante o término de relacionamentos afetivos e/ou sexuais, se encontra muito presente na pornografia de vingança e assume significados simbólicos muito bem descortinados pelo sociólogo Bourdieu (2007). Condenadas a circular à semelhança de símbolos fiduciários nas relações estritamente masculinas, as mulheres constituem utensílios úteis para produção e reprodução do capital simbólico social.

A vingança mediante a humilhação da vítima serve, assim, para demonstrar perante a si mesmo e perante os outros homens que o término de um relacionamento não diminuiu o capital simbólico adquirido pelo homem, tendo em vista que ainda assim esse pode dispor da sexualidade feminina. Essa disposição do corpo, desejo e autonomia alheia constitui capital de troca mais valioso ainda para os agressores, considerando a afirmação da masculinidade e redução da condição feminina em escalas planetárias, livres de barreiras temporais e espaciais na socialização da internet.

Nesse sentido, pesquisa (FRANKS, 2015) disponibilizada pela organização End Revenge Porn indicou que $90 \%$ das pessoas pesquisadas eram vítimas de pornografia de vingança, sendo $57 \%$ mulheres que afirmaram que o conteúdo íntimo foi disponibilizado pelo seu ex-namorado, juntamente com seu nome completo.

\subsection{Outros}

Além de estar associado às motivações popularmente conhecidas, como sextorsão e represália masculina ante a infidelidade ou término do relacionamento, a disposição da sexualidade feminina em ambientes de socialização virtual ou presencial também pode ser motivada por outros interesses, como a propaganda do comércio de exploração sexual (FRANKS, 2015).

Nesse sentido, Bartow (2008) observa que a produção e distribuição de materiais pornográficos por usuários da internet é realizada fora das estruturas convencionais da indústria pornográfica e sem fins lucrativos. Considerados material pornográfico amador, esse conteúdo pode ser carregado, publicado e compartilhado em escalas assustadoras, atraindo expectadores fascinados pela erotização da humilhação desferida contra alguém.

Outra possível explicação para a exposição não autorizada da intimidade feminina na internet é o deslocamento de vídeos e/ou imagens de sua conjuntura cotidiana para um contexto sexualizado. Exemplificando esse raciocínio, cita-se o caso da jovem Allison Stokke, estudante norte-americana de instituição do ensino médio que teve imagens do seu treino de ginástica amplamente distribuídas na internet, em que o corpo feminino fardado foi transformado em objeto de fetiche exposto por blogs eróticos para estimular a masturbação dos internautas Bartow (2008).

A exposição não autorizada da sexualidade feminina também pode estar associada ao tráfico de pessoas. De acordo com o Relatório de Tráfico de Pessoas de junho de 2007, do Departamento de Estado dos Estados Unidos, as mulheres e crianças são as principais vítimas da exploração sexual comercial, incluindo a pornografia forçada. De acordo com o referido documento, existem muitas evidências de que 
mulheres sujeitas à prostituição também são filmadas à força, conteúdo que é distribuído comercialmente (U.S. DEP'T STATE, 2007).

Continuando esse raciocínio, a pesquisa destaca que existe uma negligência institucional generalizada, que chega a impressionar, para com as vítimas de pornografia violenta, conteúdos que normalmente são anunciados de forma a realçar a violência real com que foi feita a produção (U.S. DEP'T STATE, 2007). Nessa modalidade de exposição não autorizada da intimidade feminina, observa-se largamente a incidência do mito da beleza já explicitado e teorizado por Naomi Wolf, que erotiza a violência sexual (WOLF, 1992).

Por último, a exposição não autorizada da sexualidade feminina também pode acontecer em um contexto de violação dos deveres profissionais de médicos e enfermeiros, por exemplo. Nesse sentido, Franks (2015) destaca registros que aconteceram nos EUA, em que enfermeiros foram flagrados capturando fotos íntimas de idosos e deficientes para expor nas redes sociais.

\section{Abrangência da exposição não autorizada da sexualidade feminina}

Variados estudos indicam a alta incidência da violência contra a mulher nas redes. Nesse sentido, pesquisa demonstra a ampla conexão entre as tecnologias da informação e a violência, apontando que os agressores utilizam as tecnologias de variadas formas visando o controle sobre suas vítimas. Assim, é comum o monitoramento das atividades femininas mediante a utilização de serviços de localização disponíveis nos telefones móveis, que podem ser utilizados também para controle das mensagens de texto e/ou chamadas (FIALOVA; FASCENDINI, 2012).

Entre as principais formas de abusocitadas pelo relatório contra mulheres através das tecnologias da informação, estão: perseguição online e ou cibermolestamento; estupros, a partir do registro dos abusos e distribuição do material constando a violação; fomentação à cultura do estupro, quando a tecnologia perpetua o uso da cultura para justificar ou ignorar atos de violência contra a mulher.

Quanto à pornografia de vingança, o estudo pontua que é técnica de baixo custo e pouco esforço para os agressores, que podem utilizar vários mecanismos para reprodução e distribuição infinitas do conteúdo íntimo alheio, sujeitando as vítimas a um linchamento moral permanente, considerando o contexto de "tudo se registra, nada se esquece", típico da internet:

\footnotetext{
[...] Os abusadores também podem manipular fotografias de mulheres para convertê-las em imagens pornográficas e distribuí-las com informação pessoal, como número de telefone e endereço. Também são filmados momentos de violação e agressão sexual, e os espectadores ou perpetradores da violência os distribuem através da Internet e de telefones móveis. Os perpetradores deste tipo de violência registram estas imagens por diferentes razões. Em alguns casos, ameaçam distribuí-las para extorquir uma mulher ou forçá-la a permanecer em uma relação abusiva. Também ocorre a distribuição de imagens e filmes para humilhar e difamar mulheres [...]. Em outros casos, os abusadores circulam estas imagens e gravações como um 'hobby' para ganhar prestígio entre seus pares ou simplesmente para mostrar que podem fazê-lo (FIALOVA; FASCENDINI, 2012, p. 119).
}

Dadas as múltiplas possibilidades de interatividade características da era virtual, a sexualidade das vítimas pode ser exposta de infinitas formas em contextos de socializações virtuais ou presenciais, compreendendo diferentes mecanismos, muito embora o objetivo central da exposição seja a humilhação das mulheres, seguido do controle sobre seu comportamento.

Nesse sentido, constituem as principais de fontes de obtenção do conteúdo íntimo pelos autores de extorsão, estupro virtual e pornografia de vingança: invasão de dispositivo eletrônico, o sexting, o roubo de fotos e vídeos, o registro de momentos íntimos sem o conhecimento ou consentimento das vítimas, entre outros.

Constituem meios de expor a sexualidade feminina a divulgação e compartilhamento de fotos, vídeos, áudios, textos, mensagens, prints, boatos verdadeiros ou não, informações confidenciais e quaisquer outros meios e condutas aptas a expor a intimidade das vítimas nas esferas pública, social, familiar, profissional, interpessoal, religiosa, política e subjetiva. 
Constituem ambientes de exposição da sexualidade feminina as socializações virtuais e presenciais, chamando-se a atenção para a maior gravidade da exposição virtual, haja vista a potencialidade de causar prejuízos irreversíveis para a vida das vítimas no contexto da ausência de barreiras físicas e temporais, característica da internet.

\section{Conclusão}

A exposição intencional e deliberada da sexualidade feminina, seja como vingança em virtude de término ou traição afetiva, seja como forma de extorsão com a finalidade de obter vantagens patrimoniais e/ ou sexuais, seja, ainda, como manifestação do simples desejo de constranger mulheres em público, é uma prática que tem apresentado larga incidência na modernidade. Nesse contexto, ter a intimidade amplamente revelada e julgada no âmbito familiar, profissional, religioso, moral e social constitui um pesadelo para as mulheres na maior parte das sociedades ocidentais, marcadas pelo machismo e patriarcado.

Tal violência se contextualiza, dessa forma, com as diferenciações sexistas de educação de pessoas de ambos os gêneros, que constituem o plano de fundo para a agressão psicológica, sexual, moral e patrimonial, crimes tutelados pela Lei Maria da Penha quando essas condutas são perpetradas em um contexto de violência intrafamiliar.

Em uma perspectiva ampla, a exposição não autorizada da sexualidade feminina pode assumir múltiplas tipificações penais, sendo o gênero o denominador comum em todas elas, à proporção que a mulher vítima é, simbolicamente, colocada em posição de submissão às deliberações do seu agressor, que pode utilizar as coerções para obter vantagens patrimoniais e/ou sexuais, o controle constante de todos os passos das vítimas e/ou a humilhação delas na esfera pública.

Dessa forma, independentemente das motivações que expliquem as ameaças de compartilhamento e efetiva divulgação da sexualidade feminina na esfera pública, o gênero é um elemento central, haja vista sua incidência no polo ativo do crime, majoritariamente representado pelos homens, e no polo passivo, normalmente ocupado por mulheres, e as relações desiguais de poder em todas as nuanças das condutas.

A coerção psicológica, voltada à obtenção de vantagens patrimoniais ante a possibilidade de exposição íntima na internet, está relacionada ao crime de extorsão, tipificado no art. 158 do Código Penal brasileiro, que protege o patrimônio, lesado ante à vulnerabilidade física e/ou psíquica das vítimas.

Atentando contra o direito de liberdade das vítimas, entendido como ausência de coação na realização de escolhas pessoais, o constrangimento ilegal também pode estar associado à disposição da sexualidade feminina para, por exemplo, obrigar a vítima à continuidade de uma relação não desejada, desencorajar denúncias de abusos e violências, impor ao sujeito passivo a adoção de determinados comportamentos (como exclusão de pessoas do seu círculo de amizades) e demonstrações públicas de afeto, impor a retratação ante queixas relacionadas às agressões sofridas, entre outros.

Diante de todo o exposto, observa-se que a sextorsão é um fenômeno que admite adequação típica plural, existindo sempre que uma relação de poder seja o contexto para a prática de estupro, constrangimento ilegal ou extorsão com base na ameaça de divulgar conteúdo íntimo feminino.

Além disso, a disposição e exposição da sexualidade feminina também pode estar associada ao desejo de vingança ante traição e término afetivo, o que exemplifica ajustamento da conduta do agressor a uma ordem masculina invisibilizada, naturalizada e sexista, inclusive no âmbito do sistema de justiça. Imprimindo em sua formação a necessidade de recurso à violência em situações de vingança, essa conjuntura também fabrica, no meio social, expectativas para as reações ideais de um homem rejeitado, inseguro e com baixa autoestima, como vingar-se, supostamente exercendo uma forma de recuperar no meio social a honra minorada pela decisão feminina do término.

Destaca-se que, apesar do gênero como denominador comum de todas os crimes pautados na disposição e exposição da sexualidade feminina, a pornografia de vingança apresenta um elemento diferenciador, qual seja: a maior intensidade do sofrimento vivenciado pela vítima, tendo em vista que a decepção e a angústia 
característicos dos rompimentos amorosos somam-se à humilhação e ao constrangimento da exposição íntima por um agressor com quem a vítima manteve um relacionamento afetivo ou sexual, impondo-lhe uma vulnerabilidade característica adicional, com alto poder lesivo à sua saúde psicológica.

Além de estar associada às motivações popularmente conhecidas, a disposição da sexualidade feminina em ambientes de socialização virtual ou presencial também pode ser motivada por outros interesses, como, a propaganda do comércio de exploração sexual.

Dada a multiplicidade de mecanismos, condutas e características da internet que facilitam e intensificam a exposição sexual feminina, imprimindo nas vítimas os sentimentos de culpa e redução da autoestima, as abordagens penais dedicadas a tipificar os crimes de gênero na internet devem ser caracterizadas pela máxima versatilidade jurídica, tipificando-se a exposição em ambientes virtuais e presenciais, nos mais variados veículos de interação humana e esferas do relacionamento interpessoal, considerando-se sempre que o gênero é o elemento em comum entre todas as condutas criminosas descritas no presente estudo.

\section{Referências}

BARTOW, Ann. Pornography, Coercion, and Copyright Law 2.0. Vanderbilt Journal of Entertainment and Technology Law, [S.I.], v. 10, n. 4, 2008.

BEAUVOIR, Simone. O segundo sexo: fatos e mitos. São Paulo: Difusão Européia do Livro, 1960.

BITENCOURT, Cezar Roberto. Tratado de direito penal: parte especial: dos crimes contra a pessoa São Paulo: Saraiva, 2012. v. 2.

BITENCOURT, Cezar Roberto. Tratado de direito penal: parte especial: dos crimes contra o patrimônio até dos crimes contra o sentimento religioso e o respeito aos mortos. São Paulo: Saraiva, 2012. v. 3.

BITENCOURT, Cezar Roberto. Tratado de direito penal: parte especial: crimes contra a dignidade sexual até crimes contra a fé pública. 12. ed. São Paulo: Saraiva, 2018. v. 4.

BOURDIEU, Pierre. A dominação masculina. Rio de Janeiro: Bertrand Brasil, 2007.

BRASIL. Lei $n^{\circ}$ 11.340, de 7 de agosto de 2006 [Lei Maria da Penha]. Cria mecanismos para coibir a violência doméstica e familiar contra a mulher, nos termos do § 80 do art. 226 da Constituição Federal, da Convenção sobre a Eliminação de Todas as Formas de Discriminação contra as Mulheres e da Convenção Interamericana para Prevenir, Punir e Erradicar a Violência contra a Mulher; dispõe sobre a criação dos Juizados de Violência Doméstica e Familiar contra a Mulher; altera o Código de Processo Penal, o Código Penal e a Lei de Execução Penal; e dá outras providências. Brasília, DF, 2006.

BRASIL. Lei n $^{\circ}$ 13.104, de 9 de março de 2015. Altera o art. 121 do Decreto-Lei no 2.848, de 7 de dezembro de 1940 - Código Penal, para prever o feminicídio como circunstância qualificadora do crime de homicídio, e o art. 10 da Lei no 8.072, de 25 de julho de 1990, para incluir o feminicídio no rol dos crimes hediondos. Brasília, DF, 2015.

BRASIL. Lei $n^{\circ}$ 13.718, de 24 de setembro de 2018. Altera o Decreto-Lei $n^{\circ} 2.848$, de 7 de dezembro de 1940 (Código Penal), para tipificar os crimes de importunação sexual e de divulgação de cena de estupro, tornar pública incondicionada a natureza da ação penal dos crimes contra a liberdade sexual e dos crimes sexuais contra vulnerável, estabelecer causas de aumento de pena para esses crimes e definir como causas de aumento de pena o estupro coletivo e o estupro corretivo; e revoga dispositivo do Decreto-Lei n 3.688, de 3 de outubro de 1941 (Lei das Contravenções Penais). Brasília, DF, 2018.

BRASIL. Superior Tribunal de Justiça. Súmula n 96. TJ-RJ, AC 0021566-53.2012.8.19.0204. Rel. Des. Cairo Ítalo França David. Diário de Justiça eletrônico. Brasília, DF, 13 set. 2016.

BRUNO, Aníbal. Crimes contra a pessoa. Rio de Janeiro: Editora Rio, 1976.

BUZZI, Vitória de Macedo. Pornografia de vingança: Contexto histórico-social e abordagem no direito brasileiro. 2015. Monografia (Curso de Direito) - Universidade Federal de Santa Catarina, Florianópolis, 2015. Disponível em: https://repositorio.ufsc.br/xmlui/handle/123456789/133841. Acesso em: 04 out. 2016. 
DIAS, Maria Berenice. A Lei Maria da Penha na justiça: a efetividade da Lei 11.340/2006 de combate à violência doméstica e familiar contra a mulher. São Paulo: Revista dos Tribunais, 2008.

ECGLOBAL. Relatório Sexting no Brasil: uma ameaça desconhecida. [S.I.]. 13 maio 2013. 24 slides. Disponível em: https://www.slideshare.net/ecglobal/relatorio-sexting-brasilpt. Acesso em: 25 mar. 2015.

FRANKS, Mary Anne. Drafting an effective revenge porn law: a guide for legislators. [S.I.: S.n.], 2015. Disponível em: https://www.cybercivilrights.org/wp-content/uploads/2016/09/Guide-for-Legislators-9.16. pdf. Acesso em: 7 maio 2015.

JESUS, Damásio de. Direito penal: parte especial; Crimes contra a pessoa e crimes contra o patrimônio. São Paulo: Saraiva, 2013. v. 2.

JESUS, Damásio de. Violência contra a mulher: aspectos criminais da Lei. 11.540/2006. São Paulo: Saraiva, 2010.

KOHLRAUSCH, André Rodrigo. A “pornografia de vingança” e a Lei Maria da Penha: crime de exposição pública de intimidade sexual. 2017. Monografia (Graduação em Direito) - Universidade do Vale do Taquari, Lajeado, 2017. Disponível em: http://hdl.handle.net/10737/1879. Acesso em: 12 mar. 2018.

$\mathrm{MOCHO}$, Nathalia de Azevedo. Crimes cibernéticos: pornografia de vingança. 2016. Monografia (Graduação em Direito) - Universidade Federal Fluminense, Rio de Janeiro, 2016. Disponível em: https:// app.uff.br/riuff/bitstream/1/2455/1/Nathalia\%20Mocho\%20-\%20Crime\%20Cybern\%C3\%A9tico,\%20 Pornografia\%20de\%20vingan\%C3\%A7a..pdf. Acesso em: 24 mar. 2017.

PINHEIRO, Rossana Barros. Tratamento da pornografia de vingança pelo judiciário maranhense: avaliando a atual divisão de competências entre Vara de Violência Doméstica e Familiar contra Mulher e Juizado Especial Criminal a partir do critério efetividade. 2018. 185f. Dissertação (Programa de PósGraduação em Direito) - Universidade Federal do Maranhão, São Luís, 2018. Disponível em: https:// tedebc.ufma.br/jspui/handle/tede/2431. Acesso em: 12 jan. 2018.

FIALOVA, Katerina; FASCENDINI, Flavia. Vozes dos espaços digitais: violência contra a mulher relacionada à tecnologia. [S.I.], maio 2012. Disponível em: http://www.genderit.org/sites/default/ upload/38_violenciacontramulher_politics12.pdf. Acesso em: 12 maio 2017.

RIO DE JANEIRO. Tribunal de Justiça do Rio de Janeiro. Embargos Infringentes n 250/99. Rel. Des. Wilson Marques. Diário Oficial do Rio de Janeiro, 04 out. 1999.

SILVA, Artenira Silva; ALVES, José Márcio Maia. A tipificação da lesão à saúde psicológica: Revisitando o art. 129, do Código Penal à luz da Lei Maria da Penha. In: SILVA, Artenira Silva; MANSO, Almudena García (org.). A aplicação da Lei Maria da Penha no Maranhão. São Luís: EDUFMA, 2016.

STREIT, Maíra. Dupla sertaneja cria polêmica com a música "Vou jogar na internet". Revista Fórum, abr. 2015. Disponível em: https://www.revistaforum.com.br/dupla-sertaneja-cria-polemica-com-a-musica-voujogar-na-internet/. Acesso em: 2 jun. 2017.

SYDOW, Spencer Toth; CASTRO, Ana Lara Camargo de. Sextorsão. Revista dos Tribunais, São Paulo, v. 959, set. 2015. Disponível em: http://www.mpsp.mp.br/portal/page/portal/documentacao_e_divulgacao/ doc_biblioteca/bibli_servicos_produtos/bibli_boletim/bibli_bol_2006/RTrib_n.959.09.PDF. Acesso em: 12 jan. 2018.

U.S. DEP'T STATE. Trafficking in persons report. 2007. Disponível em: http://www.state.gov/ documents/organization/82902.pdf. Acesso em: 12 maio 2018.

VARELA, Nuria. Feminismo para principiantes. Barcelona: Ediciones B. S. A., 2008.

WOLF, Naomi. O mito da beleza. Rio de Janeiro: Rocco, 1992.

Recebido em: 29/08/2018

Aprovado em: 22/10/2018 